\title{
Response surface methodology as an efficient tool for optimizing carbon adsorbents for $\mathrm{CO}_{2}$ capture
}

\author{
M.V. Gil, M. Martínez, S. García, F. Rubiera, J.J. Pis, C. Pevida* \\ Instituto Nacional del Carbón, INCAR-CSIC, Apartado 73, 33080 Oviedo, Spain
}

\begin{abstract}
Phenol-formaldehyde resins and a low-cost biomass residue, olive stones (OS), were used to prepare five activated carbons for $\mathrm{CO}_{2}$ separation at atmospheric pressure, i.e., in post-combustion processes or from biogas and bio-hydrogen streams. Two phenolformaldehyde resins were synthesized: Resol, obtained by using alkaline environment, and Novolac, synthesized in the presence of an acid catalyst. Carbon precursors were prepared by mixing both resins with $\mathrm{KCl}$ or by mixing the Novolac resin with $\mathrm{OS}$. The precursors were carbonized under an inert atmosphere of $\mathrm{N}_{2}$ at different temperatures. The last stage in the synthesis of the adsorbents involved physical activation with carbon dioxide, which was carried out at different temperatures and burn-off degrees. Response surface methodology (RSM) is proposed as a tool for rapidly optimizing the activation parameters in order to obtain the highest possible $\mathrm{CO}_{2}$ capture capacity of activated carbons. The optimum values of activation temperature and burn-off degree that maximize $\mathrm{CO}_{2}$ uptake by the activated carbons at $35^{\circ} \mathrm{C}$ and atmospheric pressure were obtained within the experimental region. A value of $\mathrm{CO}_{2}$ adsorption capacity of 9.3 wt.\% was achieved. Activated carbons derived from Novolac phenol-formaldehyde
\end{abstract}

\footnotetext{
* Corresponding author. Tel.: +34 985119 090; Fax: +34 985297662

E-mail address: cpevida@incar.csic.es (C. Pevida)
} 
resin type and from OS showed great potential as adsorbents for $\mathrm{CO}_{2}$ capture at atmospheric pressure.

Keywords: Phenol-formaldehyde resin; Activation temperature; Burn-off degree; Activated carbon; $\mathrm{CO}_{2}$ capture; Response surface methodology

\section{Introduction}

It is widely accepted that climate change is a global phenomenon influenced by greenhouse gas emissions to the atmosphere, $\mathrm{CO}_{2}$ being the main greenhouse gas contributing to global warming. The main source of $\mathrm{CO}_{2}$ emissions is the production of energy from fossil fuels. Although some measures are already being implemented, such as increasing the use of renewables and improving the efficiency of energy conversion processes, in the short-to-medium term carbon capture and storage (CCS) will be necessary in order to reduce $\mathrm{CO}_{2}$ emissions to the atmosphere. $\mathrm{CO}_{2}$ capture is the most costly component of the CCS process [1]. This has led to intensive research aimed at the production of $\mathrm{CO}_{2}$ capture materials which can achieve significant levels of $\mathrm{CO}_{2}$ uptake.

Adsorption is considered one of the most promising technologies for $\mathrm{CO}_{2}$ capture and different types of adsorbents, such as zeolites and activated carbons, have been used for this purpose [2-4]. Zeolites are the most extensively studied adsorbents of $\mathrm{CO}_{2}$, due to their high selectivity towards $\mathrm{CO}_{2}$. However, activated carbons have a high adsorption capacity at ambient pressures and present important advantages over zeolites, such as their hydrophobicity, their significant lower cost and the lower amount of energy needed to regenerate them. Adsorption with activated carbons at atmospheric pressure is a useful technology for postcombustion $\mathrm{CO}_{2}$ capture, as well as for the 
separation of $\mathrm{CO}_{2}$ from $\mathrm{CH}_{4} / \mathrm{CO}_{2}$ or $\mathrm{H}_{2} / \mathrm{CO}_{2}$ mixtures to obtain a stream of high pure methane or bio-hydrogen, respectively.

The process most frequently used to capture $\mathrm{CO}_{2}$ at industrial scale is chemical absorption with amines. Nevertheless, this technology has certain drawbacks, such as the high energy requirement for sorbent regeneration, amine losses due to evaporation, corrosion problems or the thermal and chemical degradation of the amines in the presence of oxygen. On the other hand, to separate $\mathrm{CO}_{2}$ from biogas streams, many technologies are used, such as water washing, amine scrubbing or vacuum pressureswing adsorption (VPSA). Amine scrubbing is the most economical upgrading process, but only for high flowrates. VPSA seems to be a suitable process for locations with small and medium flowrates and with mild temperatures [5].

The adsorption capacity of an activated carbon is mainly dependent on its pore structure but it is also strongly influenced by its surface chemistry. These materials can be obtained from almost any carbonaceous product by a process of carbonization followed by an activation step. However, the use of naturally occurring precursors to produce activated carbons limits the purity, strength and physical form of the endproduct materials. This drawback can be overcome by using polymeric precursors, where the reproducibility and purity of the precursor is within the control of the manufacturer, and the physical forms and structures can be tailored by means of the polymer production process [6]. Phenolic resins constitute a family of low-cost polymers, one of the most common being those produced from phenol and formaldehyde [7]. Phenolic resin-based activated carbons offer further advantages in that they can be produced in a wide variety of physical forms (e.g., granular or extruded, as fibres or as monolithic structures), they allow a close control of porosity, and they 
have a very low level of impurities and a good physical strength [7-9]. Furthermore, biomass residues, such as olive stones, are a low-cost and relatively abundant byproduct that can be used as a feedstock for the production of microporous activated carbons [10-11].

Response surface methodology (RSM) is a multivariate statistical technique used to optimize processes, i.e., to discover the conditions in which to apply a procedure in order to obtain the best possible response in the experimental region studied. This methodology involves the design of experiments and multiple regression analysis as tools to assess the effects of two or more independent variables on dependent variables [12]. One additional advantage is the possibility of evaluating the interaction effect between the independent variables on the response. This technique is based on the fit of a polynomial equation to the experimental data to describe the behaviour of a set of data. In this way, a mathematical model which describes the studied process is generated. The objective is to simultaneously optimize the levels of the studied variables to attain the best possible performance of the process [13]. Recently, a number of works have been published on the application of RSM to matters related with $\mathrm{CO}_{2}$ adsorption. For example, Serna-Guerrero et al. [14] studied the optimum regeneration conditions (the temperature, pressure and flow rate of purge gas) of an amine-bearing adsorbent for $\mathrm{CO}_{2}$ removal, whereas Mulgundmath and Tezel [15] investigated the optimization of carbon dioxide recovery from a flue gas in a TPSA system in relation to the purge/feed flow ratio, purge time, purge gas temperature and adsorption pressure. García et al. [16] studied the combined effect of $\mathrm{CO}_{2}$ partial pressure and temperature on $\mathrm{CO}_{2}$ capture capacity and breakthrough time of a commercial activated carbon. 
In the present work, phenol-formaldehyde resins and olive stones were employed as precursor materials for the preparation of microporous activated carbons for use in the separation of $\mathrm{CO}_{2}$. They could then be used to capture $\mathrm{CO}_{2}$ in postcombustion processes or from biogas and bio-hydrogen streams. The $\mathrm{CO}_{2}$ capture capacity of the different activated carbons was optimized in relation to temperature and burn-off degree during the activation stage by means of response surface methodology. A rapid assessment method for studying the activation conditions was proposed using a thermogravimetric analyzer. Martín et al. [6] found that intensification of the activation process did not enhance the capture capacity of some activated carbons, whereas for others it did. This shows that every activated material requires specific activation conditions. On the other hand, an increase in the burn-off degree could be justified, economically speaking, if a significant increase in the working capacity of the adsorbent were attained, since, as the burn-off increases, the pore volume gradually develops at the expense of a reduction in the final carbon yield. The objective of this study was to determine the optimum values of activation temperature and burn-off degree for each activated carbon, so as to maximize the $\mathrm{CO}_{2}$ capture capacity within a given experimental region.

\section{Materials and methods}

\subsection{Synthesis of materials}

Phenol-formaldehyde resins and a low-cost biomass residue from the Spanish food industry, olive stones (OS), were used as starting materials. Two types of phenolformaldehyde resins were synthesized. The first one was obtained by basic catalysis using sodium hydroxide $(\mathrm{NaOH})$ and is commonly referred to as Resol. In this case a 
2.5:1 formaldehyde-to-phenol ratio was used to obtain the Re resin sample. The second type of resin was synthesized by acid catalysis with hydrochloric acid $(\mathrm{HCl})$ and is known as Novolac. In this case two formaldehyde-to-phenol mole ratios were used, 1:1 and 1:1.22, to yield the No1 and No2 resin samples respectively. Phenol (99.4\%, BDH Prolabo) and formaldehyde (37 wt. $\%$ in $\mathrm{H}_{2} \mathrm{O}, \mathrm{BDH}$ Prolabo) were employed to synthesize the resins. During the synthesis, the phenol-formaldehyde solution was mixed with the catalyst (acid or basic) in a flask equipped with a reflux condenser, stirred and heated up to the desired temperature $\left(95-100^{\circ} \mathrm{C}\right)$. Once the synthesis had ended, the resins were cured, first in a rotary evaporator at $40-70{ }^{\circ} \mathrm{C}$ under vacuum (absolute pressure $48-100$ mbar) and then in a forced-air convection oven at $60-100{ }^{\circ} \mathrm{C}$. Finally, the cured resins and the olive stones were ground and sieved to obtain a particle size fraction of $1.0-3.35 \mathrm{~mm}$.

Carbon precursors were then prepared by incorporating potassium chloride $(\mathrm{KCl})$ to the $\mathrm{Re}$ and No1 cured resins, which were impregnated with $\mathrm{KCl}$ at ambient temperature (ReKCla and No1KCla precursors) or boiled with a saturated $\mathrm{KCl}$ solution (ReKClb and No1KClb precursors). However, the No2 cured resin was used as additive to the olive stones in a 80:20 wt. proportion of OS:resin. This blend was then mixed with hexamethylenetetramine $(28.6 \%)$ and heated at $170{ }^{\circ} \mathrm{C}$ for $30 \mathrm{~min}$ (No2OS precursor). The precursors were then carbonized in a horizontal furnace under a nitrogen flow rate of $50 \mathrm{~mL} \mathrm{~min}^{-1}$. The ReKCla and No1KCla precursors, prepared at ambient temperature, were carbonized at $600{ }^{\circ} \mathrm{C}$, which yielded the ReKCla-600 and No1KCla-600 carbonized samples. The ReKClb and No1KClb precursors, prepared at boiling temperature, were carbonized at $1000{ }^{\circ} \mathrm{C}$, to give the $\mathrm{ReKClb}-1000$ and 
No1KClb-1000 carbonized samples. Finally, the No2OS precursor was carbonized at $1000^{\circ} \mathrm{C}$, to give the No2OS-1000 carbonized sample.

\subsection{Study of physical activation with $\mathrm{CO}_{2}$ using the response surface methodology}

The carbonized materials were physically activated with $\mathrm{CO}_{2}$ in a thermobalance in a $10 \mathrm{~mL} \mathrm{~min}^{-1}$ stream of $\mathrm{CO}_{2}$ at different temperatures. The duration of the activation process was dependent on the degree of burn-off. The response surface methodology (RSM) was used to evaluate the effect of temperature and burn-off degree during the activation stage on the $\mathrm{CO}_{2}$ capture capacity of the activated carbons. The objective of this study was to determine the optimum values of activation temperature and burn-off degree that would maximize the $\mathrm{CO}_{2}$ capture capacity of each activated carbon at $35^{\circ} \mathrm{C}$ and atmospheric pressure.

In this work, the independent variables were the activation temperature $(\mathrm{T})$ and the burn-off degree attained after the activation process (B), while the dependent variable was the $\mathrm{CO}_{2}$ capture capacity. The levels of the independent variables are the different values at which the experiments must be carried out. Both independent variables were investigated at three levels, which varied depending on the carbonized material studied.

Before applying the RSM methodology, an experimental design was chosen, which defined what experiments had to be carried out in the experimental region under study as a set of different combinations of the levels of the independent variables. In this work a three-level full factorial design was chosen. This involved 13 experiments,

which are shown in Table 1, including nine factorial points and four additional replicates at the centre of the design by means of which it was possible to estimate the 
experimental error associated with the repetitions. All the experiments were executed in a random order.

In order to choose the activation temperature range for each carbonized material,

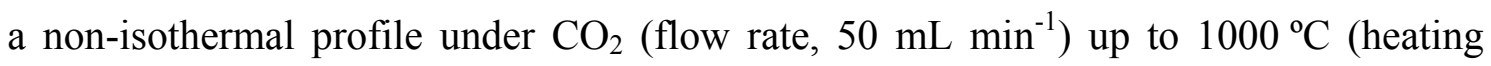
rate, $15^{\circ} \mathrm{C} \min ^{-1}$ ) was obtained for each carbonized sample using a Setaram TGA 92 thermogravimetric analyzer. From these profiles, the temperature of commencement of mass loss was assumed as the minimum activation temperature for each sample. Afterwards, isothermal profiles under $\mathrm{CO}_{2}$ (flow rate, $10 \mathrm{~mL} \mathrm{~min}{ }^{-1}$ ) at the selected activation temperatures were performed in order to calculate the time necessary to obtain the different selected burn-off degrees.

The levels of the independent variables, i.e. activation temperature and burn-off degree, were coded so that variables with different units or of different orders of magnitude could be compared. The responses would then be evenly affected, making the units of the parameters irrelevant. Codification of the levels of the variables consisted in transforming each studied real value into coordinates inside a scale with dimensionless values, which are proportional to their location in the experimental space. In Table 1 the coded values of the independent variables for all of the activated carbons are shown in parentheses. The experimental values obtained for the response variable, $\mathrm{CO}_{2}$ capture capacity, for all of the activated carbons are presented in Table 2.

The mathematical-statistical treatment of the experimental data consisted in fitting a polynomial function to the set of data. In this work, with two independent variables, $x_{1}$ and $x_{2}$, the following second-order polynomial equation was used:

$y=\beta_{0}+\beta_{1} x_{1}+\beta_{2} x_{2}+\beta_{12} x_{1} x_{2}+\beta_{11} x_{1} x_{1}+\beta_{22} x_{2} x_{2}+\varepsilon$ 
where $\beta_{0}$ is the constant term, $\beta_{1}$ and $\beta_{2}$ represent the coefficients of the linear parameters, $\beta_{12}$ represents the coefficient of the interaction parameter, $\beta_{11}$ and $\beta_{22}$ represent the coefficients of the quadratic parameters and $\varepsilon$ is the residual associated with the experiments. Multiple regression analysis was used to fit Eq. (1) to the experimental data by means of the least-squares method, which makes it possible to determine the $\beta$ coefficients that generate the lowest possible residual. The equation obtained describes the behaviour of the response in the experimental region as a function of the independent variables.

Evaluation of the fitness of the models was carried out by applying an analysis of variance (ANOVA) and a lack of fit test. A model will fit the experimental data well if it presents a significant regression and a non-significant lack of fit. To establish whether a parameter is significant, a $p$-value test with a $95 \%$ level of confidence was applied to the experimental results. The coefficient of determination adjusted by the number of variables $\left(\mathrm{Adj}-R^{2}\right)$ and the absolute average deviation (AAD) were calculated in order to check the accuracy of the model. Adj- $R^{2}$ must be close to 1.0 and the AAD between the predicted and observed data must be as small as possible. Adj- $R^{2}$ represents the proportion of variability of the data that is accounted for by the model. The ADD is a direct parameter that describes the deviations between the experimental and calculated values and it is calculated by means of the following equation [17]:

$\operatorname{AAD}(\%)=100\left[\Sigma_{i=1}^{n}\left(\left|y_{i, \exp }-y_{i, \text { cal }}\right| / y_{i, \exp }\right)\right] / n$

where $y_{i, \exp }$ and $y_{i, \text { cal }}$ are the experimental and calculated responses, respectively, and $n$ is the number of experiments. The statistical analyses were carried out by SPSS Statistics 17.0 software. 
The model obtained can be three-dimensionally represented as a surface (response surface plot) and the best operational conditions inside the studied experimental region can be found by visual inspection. A two-dimensional display of the surface plot generates the contour plot, where the lines of constant response are drawn on the plane of the independent variables. Response surface and contour plots were generated using the software SigmaPlot 8.0. In this way, it was possible to obtain the optimum values for each studied independent variable that would optimize the response in the experimental region studied.

\section{4. $\mathrm{CO}_{2}$ capture capacity}

The $\mathrm{CO}_{2}$ capture capacity of the adsorbents at $35^{\circ} \mathrm{C}$ and atmospheric pressure was assessed in a Mettler Toledo TGA/DSC 1 thermogravimetric analyzer. Prior to the adsorption measurements, the samples were dried at $100{ }^{\circ} \mathrm{C}$ under an inert atmosphere (Ar, $50 \mathrm{~mL} \mathrm{~min}^{-1}$ ). Afterwards, a $\mathrm{CO}_{2}$ adsorption test was conducted under a $\mathrm{CO}_{2}$ flow rate of $100 \mathrm{~mL} \min ^{-1}$ at $35^{\circ} \mathrm{C}$ up to constant weight. The maximum $\mathrm{CO}_{2}$ uptake at atmospheric pressure and $35^{\circ} \mathrm{C}$ was evaluated from the increase in mass experienced by the sample and it was expressed in terms of mass of $\mathrm{CO}_{2}$ per mass of dry adsorbent.

\section{Results and discussion}

\subsection{Validation of the methodology of activation in a thermogravimetric analyzer}

In order to evaluate the possibility of carrying out the activation process in a thermobalance as a rapid method for the evaluation of the activation parameters, experiments of activation with $\mathrm{CO}_{2}$ were performed in a vertical furnace and in a thermogravimetric analyzer. The No2OS-1000 carbonized material was used for this 
purpose. Firstly, a non-isothermal profile under $\mathrm{CO}_{2}$ (flow rate, $50 \mathrm{~mL} \mathrm{~min}{ }^{-1}$; heating rate, $15^{\circ} \mathrm{C} \mathrm{min}^{-1}$ ) up to $1000{ }^{\circ} \mathrm{C}$ was obtained for the carbonized material using a Setaram TGA 92 thermogravimetric analyzer. Fig. 1a shows the mass loss of the sample as a function of temperature. From this profile, an activation temperature of $950{ }^{\circ} \mathrm{C}$ was selected for the comparison of the results obtained from the thermogravimetric analyzer and furnace.

An isothermal profile under $\mathrm{CO}_{2}$ at $950{ }^{\circ} \mathrm{C}$ was then carried out. Firstly, the carbonized sample was maintained at room temperature under an inert atmosphere (Ar, $50 \mathrm{~mL} \mathrm{~min}{ }^{-1}$ ) for $10 \mathrm{~min}$ and then was heated up to $950{ }^{\circ} \mathrm{C}$ (heating rate, $50{ }^{\circ} \mathrm{C} \mathrm{min}^{-1}$ ), this temperature being maintained for $10 \mathrm{~min}$. Then, the atmosphere was changed to $\mathrm{CO}_{2}$ (flow rate, $10 \mathrm{~mL} \mathrm{~min}^{-1}$ ) and the temperature was maintained at $950{ }^{\circ} \mathrm{C}$ for $10 \mathrm{~h}$. Finally, the sample was cooled down to room temperature under inert atmosphere (Ar, $50 \mathrm{~mL} \mathrm{~min}^{-1}$; cooling rate, $50{ }^{\circ} \mathrm{C} \mathrm{min}^{-1}$ ). Fig. $1 \mathrm{~b}$ shows the mass loss of the sample as a function of time. The time needed to obtain the selected burn-off degree was determined from this plot. Thus, carbons with degrees of burn-off of 29 and 38\% were obtained after total times of 58 and 64 min (i.e. 20 and 26 min under $\mathrm{CO}_{2}$ atmosphere), respectively.

Simultaneous activation experiments with $\mathrm{CO}_{2}$ were carried out in a vertical furnace (500 mg of sample approximately) in a $10 \mathrm{~mL} \mathrm{~min}{ }^{-1}$ stream of $\mathrm{CO}_{2}$ up to $950{ }^{\circ} \mathrm{C}$. The duration of the activation processes were 1.1 and $1.3 \mathrm{~h}$ and carbons with burn-off degrees of 28 and $40 \%$, respectively, were obtained.

The $\mathrm{CO}_{2}$ capture capacity of the activated carbons, obtained in the thermobalance and vertical furnace, was assessed in a Mettler Toledo TGA/DSC 1 thermogravimetric analyzer, as explained above. Fig. 1c shows the $\mathrm{CO}_{2}$ capture capacity 
at $35^{\circ} \mathrm{C}$ and atmospheric pressure with time for the activated carbons obtained in the thermobalance and in vertical furnace. As can be seen, the samples obtained in both experimental devices presented similar behaviours under these conditions, i.e., the $\mathrm{CO}_{2}$ capture capacity increased with the increase in burn-off degree. In addition, the differences in capture capacity between carbons were very small. It can be seen that the $\mathrm{CO}_{2}$ capture capacity of the samples obtained in the thermobalance was only slightly higher (around $0.2 \%$ ) than that of the samples activated in the furnace.

The structure of the activated carbons obtained in the furnace and thermobalance is undoubtedly different. However, from these results, it can be concluded that the $\mathrm{CO}_{2}$ activation in a thermogravimetric analyzer may be used as a reliable tool to rapidly assess the effect of the activation parameters on the $\mathrm{CO}_{2}$ capture capacity.

Therefore, to study the $\mathrm{CO}_{2}$ capture capacity as a function of the activation characteristics using response surface methodology, the thermobalance was used in order to reduce the experimental time.

\subsection{Optimization of the activation parameters by response surface methodology}

A systematic study using RSM has been carried out to examine the combined effect of activation temperature and burn-off on $\mathrm{CO}_{2}$ capture capacity. Tables 3 and 4 show the results of fitting Eq. (1) to the experimental data by multiple regression analysis, and those obtained from evaluating the fitness of the model by means of ANOVA, together with the Adj- $R^{2}$ and AAD values.

The ANOVA tests showed that the models for $\mathrm{CO}_{2}$ capture capacity were statistically significant at a 95\% confidence level ( $p$-value $<0.05)$, whereas their lack-of- 
fit was found to be statistically non-significant at a $95 \%$ confidence level ( $p$ value $>0.05)$.

Tables 3 and 4 also show which of the terms in the models were statistically significant at a 95\% confidence level $(p$-value $<0.05)$, and those that were not statistically significant ( $p$-value $>0.05$ ) were eliminated from the models. The Adj- $R^{2}$ and the AAD values were found to be acceptable, between $0.806-0.949$ and $1.4-8.1 \%$, respectively.

Once the non-significant terms were eliminated, the coded coefficient values were decoded in order to obtain the polynomial models for the response variables as a function of the true independent variables. The models obtained for all the activated carbons were as follows:

$\mathrm{CO}_{2}$ uptake $_{\text {ReKCla-600 }}($ wt. $\%)=-56.5446+0.1710 \mathrm{~T}+0.1863 \mathrm{~B}-0.0003 \mathrm{~T} \cdot \mathrm{B}$

$-0.0001 \mathrm{~T}^{2}$

$\mathrm{CO}_{2}$ uptake $_{\text {ReKClb-1000 }}($ wt. $\%)=-97.8905+0.2782 \mathrm{~T}+0.0367 \mathrm{~B}-0.0002 \mathrm{~T}^{2}$

$\mathrm{CO}_{2}$ uptake $_{\text {No1KCla- } 600}($ wt.\%) $=-20.4159+0.0668 \mathrm{~T}+0.2134 \mathrm{~B}-0.0002 \mathrm{~T} \cdot \mathrm{B}$

$-0.00004 \mathrm{~T}^{2}-0.0016 \mathrm{~B}^{2}$

$\mathrm{CO}_{2}$ uptake $_{\mathrm{No} 1 \mathrm{KClb}-1000}($ wt. $\%)=-17.4048+0.0622 \mathrm{~T}-0.00004 \mathrm{~T}^{2}$

$\mathrm{CO}_{2}$ uptake $_{\text {No2OS-1000 }}\left(\right.$ wt.\%) $=-187.2095+0.4129 \mathrm{~T}-0.0002 \mathrm{~T}^{2}$

Figs. 2 and 3 present the response surface plots and the contour plots for the $\mathrm{CO}_{2}$ capture capacity as a function of the independent variables, activation temperature and burn-off, for all the activated carbons. For the ReKCla-600 material (Fig. 2a), at high temperatures the $\mathrm{CO}_{2}$ capture capacity decreased as the degree of burn-off increased. However, at lower temperatures this effect was not very noticeable and the burn-off had very little influence on $\mathrm{CO}_{2}$ uptake. This is shown by the interaction term, $\mathrm{T} \cdot \mathrm{B}$, in Eq. 
(2). In addition, a curvature can be seen in the response surface and the contour plot isolines, indicating that a maximum response is obtained in the temperature range studied. This is also shown by the quadratic term, $\mathrm{T}^{2}$, in Eq. (2). Thus, the highest $\mathrm{CO}_{2}$ capture capacity (3.6 wt.\%) was obtained at an activation temperature of $694^{\circ} \mathrm{C}$ and a burn-off degree of $10 \%$. Below this temperature, $\mathrm{CO}_{2}$ capture capacity was hardly affected at all by the burn-off degree, while above this temperature, $\mathrm{CO}_{2}$ uptake decreased with burn-off. This may indicate that at high temperatures the activation is so severe that the increase in the burn-off value probably causes a reduction in the micropore volume due to the collapse of adjacent pore walls, resulting in a lower $\mathrm{CO}_{2}$ capture capacity.

For the ReKClb-1000 carbonized material (Fig. 2b), the $\mathrm{CO}_{2}$ capture capacity increased as the degree of burn-off increased over the entire temperature range studied, since no interaction effect between $\mathrm{T}$ and $\mathrm{B}$ was detected in the experimental region under study (the $T \cdot B$ interaction term was not statistically significant as shown in Table 3). A curvature was also observed, indicating the achievement of a maximum response. In this case, the highest $\mathrm{CO}_{2}$ capture capacity (4.4 wt.\%) was obtained at an activation temperature of $722{ }^{\circ} \mathrm{C}$ and a burn-off of $50 \%$.

For the No1KCla-600 carbonized material (Fig. 3a), a curvature was found in relation to both independent variables studied, as is shown by the quadratic terms, $\mathrm{T}^{2}$ and $\mathrm{B}^{2}$, in Eq. (4). This indicates that a maximum response was achieved within the experimental region considered. The behaviour of this sample was similar to that described for ReKCla-600. For No1KCla-600 material the highest $\mathrm{CO}_{2}$ capture capacity (9.3 wt.\%) was obtained with an activation temperature of $809^{\circ} \mathrm{C}$ and a burn-off of $22 \%$. 
Finally, for the No1KClb-1000 and the No2OS-1000 carbonized materials (Figs. $3 \mathrm{~b}$ and $3 \mathrm{c}$ ) the burn-off degree had no effect on $\mathrm{CO}_{2}$ uptake, whereas a maximum response was obtained in relation to the temperature. For both materials, the $\mathrm{CO}_{2}$ uptake values within the experimental region only changed inside a very narrow range and it might cause the non-significant effect of the burn-off degree. For No1KClb-1000 the highest $\mathrm{CO}_{2}$ capture capacity $(7.5$ wt.\%) was achieved at an activation temperature of $800{ }^{\circ} \mathrm{C}$, whereas for No2OS-1000 the highest $\mathrm{CO}_{2}$ capture capacity $(7.3$ wt.\%) was obtained at $942{ }^{\circ} \mathrm{C}$, irrespective of the burn-off value.

Therefore, it can be concluded that, in the experimental region studied, the activation parameters do not similarly influence the capture capacity of all the evaluated samples. Furthermore, RSM applied to thermogravimetric data is a useful tool to carry out the optimization of the activation process.

As pointed out above, the highest $\mathrm{CO}_{2}$ uptake at atmospheric pressure and $35^{\circ} \mathrm{C}$ corresponded to the No1KCla-600 activated carbon, which reached 9.3 wt.\%. The No1KClb-1000 and No2OS-1000 samples presented relatively high $\mathrm{CO}_{2}$ uptake values (around 7.5 wt.\%). These values are in good agreement with those of commercial activated carbons used for $\mathrm{CO}_{2}$ adsorption [18]. On the other hand, the lowest values of $\mathrm{CO}_{2}$ uptake corresponded to the activated samples from the Resol basic resin, ReKCla600 and ReKClb-1000 (3.6 and 4.4 wt.\%, respectively).

The results obtained in this work will be used to produce adsorbents at the optimum activation conditions on a larger scale and to evaluate their $\mathrm{CO}_{2}$ capture performance in mixtures of $\mathrm{CO}_{2} / \mathrm{N}_{2}, \mathrm{CO}_{2} / \mathrm{CH}_{4}$ and $\mathrm{CO}_{2} / \mathrm{H}_{2}$. To this end, $\mathrm{CO}_{2}$ adsorption-desorption cyclic tests will be conducted in a purpose-built lab-scale fixed bed reactor. 


\section{Conclusions}

Carbon adsorbents prepared from phenol-formaldehyde resin type Novolac, and a mixture of this type of resin (20 wt.\%) with olive stones ( 80 wt.\%), presented $\mathrm{CO}_{2}$ adsorption capacity values, at $35^{\circ} \mathrm{C}$ and atmospheric pressure, similar to those of commercial activated carbons (7.3-9.3 wt.\%). Response surface methodology was successfully used to evaluate the combined effect of activation temperature and burn-off degree on the $\mathrm{CO}_{2}$ capture capacity of phenol-formaldehyde resin and olive stone-based activated carbons. When interaction between $\mathrm{T}$ and $\mathrm{B}$ was detected in the experimental region under consideration, at high activation temperatures the $\mathrm{CO}_{2}$ uptake decreased with the increase in burn-off, while at low temperatures the burn-off had very little influence on $\mathrm{CO}_{2}$ uptake. In the absence of interaction, the effect of burn-off was low or nil over the temperature range studied. The optimum activation conditions (temperature and burn-off degree) for maximizing $\mathrm{CO}_{2}$ uptake were determined for all the samples.

\section{Acknowledgements}

This work was carried out with financial support from the Spanish MINECO (Project ENE2011-23467), co-financed by the European Social Fund. M.V. Gil acknowledges funding from the CSIC JAE-Doc Program co-financed by the European Social Fund.

\section{References}

[1] IPCC, IPCC special report on carbon dioxide capture and storage, Cambridge, United Kingdom and New York, 2005.

[2] S. Choi, J.H. Drese, C.W. Jones, Adsorbent materials for carbon dioxide capture from large anthropogenic point sources, ChemSusChem 2 (2009) 796-854.

[3] M.G. Plaza, C. Pevida, A. Arenillas, F. Rubiera, J.J. Pis, $\mathrm{CO}_{2}$ capture by adsorption with nitrogen enriched carbons, Fuel 86 (2007) 2204-2212. 
[4] M.G. Plaza, C. Pevida, B. Arias, J. Fermoso, A. Arenillas, F. Rubiera, J.J. Pis, Application of thermogravimetric analysis to the evaluation of aminated solid sorbents for $\mathrm{CO}_{2}$ capture, J. Therm. Anal. Calorim. 92 (2008) 601-606.

[5] C.A. Grande, A.E. Rodrigues, Layered vacuum pressure-swing adsorption for biogas upgrading, Ind. Eng. Chem. Res. 46 (2007) 7844-7848.

[6] C.F. Martín, M.G. Plaza, S. García, J.J. Pis, F. Rubiera, C. Pevida, Microporous phenol-formaldehyde resin-based adsorbents for pre-combustion $\mathrm{CO}_{2}$ capture, Fuel 90 (2011) 2064-2071.

[7] A. Knop, L.A. Pilato, Phenolic resins. Chemistry. Applications and performance, Springer-Verlag, Berlín, 1985.

[8] A.I. Foster, H.J. Linney, S.R. Tennison, R.A. Cory, D.P. Swan, The use of carbons produced from phenolic resins for flue gas desulphurization, Fuel 72 (1993) 337342.

[9] S.R. Tennison, Phenolic-resin-derived activated carbons, Appl. Catal. A: General 173 (1998) 289-311.

[10] M.G. Plaza, C. Pevida, B. Arias, M.D. Casal, C.F. Martín, J. Fermoso, F. Rubiera, J.J. Pis, Different approaches for the development of low-cost $\mathrm{CO}_{2}$ adsorbents, J. Environ. Eng. 135 (2009) 426-432.

[11] M.G. Plaza, C. Pevida, B. Arias, J. Fermoso, M.D. Casal, C.F. Martín, F. Rubiera, J.J. Pis, Development of low-cost biomass-based adsorbents for postcombustion $\mathrm{CO}_{2}$ capture, Fuel 88 (2009) 2442-2447.

[12] R.H. Myers, D.H. Montgomery, Response surface methodology, John Wiley \& Sons, USA, 1995.

[13] M.A. Bezerra, R.E. Santelli, E.P. Oliveira, L.S. Villar, L.A. Escaleira, Response surface methodology (RSM) as a tool for optimization in analytical chemistry, Talanta 76 (2008) 965-977.

[14] R. Serna-Guerrero, Y. Belmabkhout, A. Sayari, Influence of regeneration conditions on the cyclic performance of amine-grafted mesoporous silica for $\mathrm{CO}_{2}$ capture: An experimental and statistical study, Chem. Eng. Sci. 65 (2010) 41664172.

[15] V. Mulgundmath, F.H. Tezel, Optimisation of carbon dioxide recovery from flue gas in a TPSA system, Adsorption 16 (2010) 587-598.

[16] S. García, M.V. Gil, C.F. Martín, J.J. Pis, F. Rubiera, C. Pevida, Breakthrough adsorption study of a commercial activated carbon for precombustion $\mathrm{CO}_{2}$ capture, Chem. Eng. J. 171 (2011) 549-556.

[17] D. Baş, İ.H. Boyac1, Modeling and optimization I: Usability of response surface methodology, J. Food Eng. 78 (2007) 836-845.

[18] C. Pevida, M.G. Plaza, B. Arias, J. Fermoso, F. Rubiera, J.J. Pis, Surface modification of activated carbons for $\mathrm{CO}_{2}$ capture, Appl. Surf. Sci. 254 (2008) 7165-7172. 


\section{Figure captions}

Fig. 1. Validation of the methodology of activation in a thermobalance using the No2OS-1000 carbonized sample: (a) Non-isothermal profile in $\mathrm{CO}_{2}$; (b) Isothermal profile in $\mathrm{CO}_{2}$ at $950{ }^{\circ} \mathrm{C}$; (c) $\mathrm{CO}_{2}$ uptake at $35^{\circ} \mathrm{C}$ and atmospheric pressure of activated carbon samples (activation temperature $=950{ }^{\circ} \mathrm{C}$ ) obtained in a thermobalance and an oven.

Fig. 2. Response surface and contour plots for $\mathrm{CO}_{2}$ capture capacity as a function of the activation temperature and burn-off corresponding to the Resol phenol-formaldehyde resin-based activated carbons: (a) ReKCla-600 and (b) ReKClb-1000.

Fig. 3. Response surface and contour plots for $\mathrm{CO}_{2}$ capture capacity as a function of the activation temperature and burn-off corresponding to the Novolac phenol-formaldehyde resin-based activated carbons: (a) No1KCla-600, (b) No1KClb-1000 and (c) No2OS1000. 
Table 1. Levels of the independent variables, i.e. activation temperature (T) and burn-off degree (B), for all the activated carbons using a three-level full factorial design

\begin{tabular}{|c|c|c|c|c|c|c|}
\hline \multirow[t]{2}{*}{ Run } & \multicolumn{2}{|c|}{ ReKCla-600 and ReKClb-1000 } & \multicolumn{2}{|c|}{ No1KCla-600 and No1KClb-1000 } & \multicolumn{2}{|c|}{ No2OS-1000 } \\
\hline & $\mathrm{T}\left({ }^{\circ} \mathrm{C}\right)$ & $\mathrm{B}(\%)$ & $\mathrm{T}\left({ }^{\circ} \mathrm{C}\right)$ & $\mathrm{B}(\%)$ & $\mathrm{T}\left({ }^{\circ} \mathrm{C}\right)$ & $\mathrm{B}(\%)$ \\
\hline 1 & $600(-1)$ & $10(-1)$ & $600(-1)$ & $10(-1)$ & $900(-1)$ & $30(-1)$ \\
\hline 2 & $600(-1)$ & $30(0)$ & $600(-1)$ & $30(0)$ & $900(-1)$ & $40(0)$ \\
\hline 3 & $600(-1)$ & $50(+1)$ & $600(-1)$ & $50(+1)$ & $900(-1)$ & $50(+1)$ \\
\hline 4 & $700(0)$ & $10(-1)$ & $800(0)$ & $10(-1)$ & $950(0)$ & $30(-1)$ \\
\hline 5 & $700(0)$ & $30(0)$ & $800(0)$ & $30(0)$ & $950(0)$ & $40(0)$ \\
\hline 6 & $700(0)$ & $50(+1)$ & $800(0)$ & $50(+1)$ & $950(0)$ & $50(+1)$ \\
\hline 7 & $800(+1)$ & $10(-1)$ & $1000(+1)$ & $10(-1)$ & $1000(+1)$ & $30(-1)$ \\
\hline 8 & $800(+1)$ & $30(0)$ & $1000(+1)$ & $30(0)$ & $1000(+1)$ & $40(0)$ \\
\hline 9 & $800(+1)$ & $50(+1)$ & $1000(+1)$ & $50(+1)$ & $1000(+1)$ & $50(+1)$ \\
\hline 10 & $700(0)$ & $30(0)$ & $800(0)$ & $30(0)$ & $950(0)$ & $40(0)$ \\
\hline 11 & $700(0)$ & $30(0)$ & $800(0)$ & $30(0)$ & $950(0)$ & $40(0)$ \\
\hline 12 & $700(0)$ & $30(0)$ & $800(0)$ & $30(0)$ & $950(0)$ & $40(0)$ \\
\hline 13 & $700(0)$ & $30(0)$ & $800(0)$ & $30(0)$ & $950(0)$ & $40(0)$ \\
\hline
\end{tabular}


Table 2. Experimental values of $\mathrm{CO}_{2}$ capture capacity for all the activated carbons using a three-level full factorial design

\begin{tabular}{|c|c|c|c|c|c|}
\hline \multirow[t]{2}{*}{ Run } & \multicolumn{5}{|c|}{$\mathrm{CO}_{2}$ capture capacity $(\%)$} \\
\hline & ReKCla-600 & ReKClb-1000 & No1KCla-600 & No1KClb-1000 & No2OS-1000 \\
\hline 1 & 2.4 & 0.8 & 7.0 & 6.7 & 6.8 \\
\hline 2 & 2.7 & 0.8 & 7.5 & 6.4 & 7.0 \\
\hline 3 & 2.4 & 0.7 & 7.3 & 5.8 & 7.0 \\
\hline 4 & 3.5 & 2.5 & 8.6 & 7.0 & 7.1 \\
\hline 5 & 3.1 & 3.8 & 9.3 & 7.7 & 7.5 \\
\hline 6 & 2.1 & 5.0 & 8.1 & 7.3 & 7.5 \\
\hline 7 & 2.5 & 1.1 & 8.3 & 6.2 & 6.5 \\
\hline 8 & 0.4 & 3.2 & 7.4 & 5.7 & 6.7 \\
\hline 9 & 0.0 & 3.1 & 5.8 & 4.7 & 6.6 \\
\hline 10 & 3.0 & 3.7 & 9.1 & 7.9 & 7.2 \\
\hline 11 & 3.3 & 3.0 & 9.3 & 7.3 & 7.1 \\
\hline 12 & 2.7 & 3.6 & 9.5 & 7.5 & 7.3 \\
\hline 13 & 2.9 & 3.2 & 9.1 & 7.6 & 7.5 \\
\hline
\end{tabular}


Table 3. Results of multiple regression analysis and ANOVA used to fit the polynomial model to the $\mathrm{CO}_{2}$ capture capacity experimental data of the Resol phenol-formaldehyde resin-based activated carbons

\begin{tabular}{|c|c|c|c|c|}
\hline & $\begin{array}{l}\text { Coded } \\
\text { coefficient }\end{array}$ & $\begin{array}{l}\text { Sum of } \\
\text { squares }\end{array}$ & DF & $p$-value \\
\hline \multicolumn{5}{|c|}{ ReKCla-600 } \\
\hline Intersection & 2.934 & 49.945 & 1 & 0.000 \\
\hline $\mathrm{T}$ & -0.767 & 3.527 & 1 & 0.000 \\
\hline B & -0.650 & 2.535 & 1 & 0.001 \\
\hline TB & -0.625 & 1.563 & 1 & 0.002 \\
\hline $\mathrm{T}^{2}$ & -1.221 & 4.115 & 1 & 0.008 \\
\hline $\mathrm{B}^{2}$ & 0.029 & 0.002 & 1 & 0.001 \\
\hline Model & & 12.353 & 5 & 0.890 \\
\hline Residual & & 0.804 & 7 & \\
\hline Total & & 13.157 & 12 & \\
\hline Lack-of-fit & & 0.604 & 3 & 0.106 \\
\hline Pure error & & 0.200 & 4 & \\
\hline$R^{2}$ & 0.939 & & & \\
\hline $\operatorname{Adj}-R^{2}$ & 0.895 & & & \\
\hline AAD (\%) & 4.42 & & & \\
\hline \multicolumn{5}{|c|}{ ReKClb-1000 } \\
\hline Intersection & 3.579 & 74.306 & 1 & 0.000 \\
\hline $\mathrm{T}$ & 0.850 & 4.335 & 1 & 0.007 \\
\hline B & 0.733 & 3.227 & 1 & 0.014 \\
\hline TB & 0.525 & 1.103 & 1 & 0.100 \\
\hline $\mathrm{T}^{2}$ & -1.878 & 9.737 & 1 & 0.001 \\
\hline$B^{2}$ & -0.128 & 0.045 & 1 & 0.714 \\
\hline Model & & 20.696 & 5 & 0.002 \\
\hline Residual & & 2.156 & 7 & \\
\hline Total & & 22.852 & 12 & \\
\hline Lack-of-fit & & 1.684 & 3 & 0.083 \\
\hline Pure error & & 0.472 & 4 & \\
\hline$R^{2}$ & 0.906 & & & \\
\hline $\operatorname{Adj}-R^{2}$ & 0.838 & & & \\
\hline AAD (\%) & 8.12 & & & \\
\hline
\end{tabular}


Table 4. Results of multiple regression analysis and ANOVA used to fit the polynomial model to the $\mathrm{CO}_{2}$ capture capacity experimental data of the Novolac phenol-formaldehyde resin-based activated carbons

\begin{tabular}{|c|c|c|c|c|}
\hline & $\begin{array}{l}\text { Coded } \\
\text { coefficient }\end{array}$ & $\begin{array}{l}\text { Sum of } \\
\text { squares }\end{array}$ & $\mathrm{DF}$ & $p$-value \\
\hline \multicolumn{5}{|c|}{ No1KCla-600 } \\
\hline Intersection & 9.183 & 489.074 & 1 & 0.000 \\
\hline $\mathrm{T}$ & -0.050 & 0.015 & 1 & 0.643 \\
\hline B & -0.450 & 1.215 & 1 & 0.003 \\
\hline TB & -0.700 & 1.960 & 1 & 0.001 \\
\hline $\mathrm{T}^{2}$ & -1.540 & 6.547 & 1 & 0.000 \\
\hline $\mathrm{B}^{2}$ & -0.640 & 1.130 & 1 & 0.004 \\
\hline Model & & 14.595 & 5 & 0.000 \\
\hline Residual & & 0.448 & 7 & \\
\hline Total & & 15.043 & 12 & \\
\hline Lack-of-fit & & 0.336 & 3 & 0.107 \\
\hline Pure error & & 0.112 & 4 & \\
\hline$R^{2}$ & 0.970 & & & \\
\hline $\operatorname{Adj}-R^{2}$ & 0.949 & & & \\
\hline AAD $(\%)$ & 1.95 & & & \\
\hline \multicolumn{5}{|c|}{ No1KClb-1000 } \\
\hline Intersection & 7.566 & 331.975 & 1 & 0.000 \\
\hline $\mathrm{T}$ & -0.383 & 0.882 & 1 & 0.042 \\
\hline B & -0.350 & 0.735 & 1 & 0.057 \\
\hline TB & -0.150 & 0.090 & 1 & 0.453 \\
\hline $\mathrm{T}^{2}$ & -1.429 & 5.642 & 1 & 0.000 \\
\hline $\mathrm{B}^{2}$ & -0.329 & 0.300 & 1 & 0.190 \\
\hline Model & & 9.816 & 5 & 0.002 \\
\hline Residual & & 0.996 & 7 & \\
\hline Total & & 10.812 & 12 & \\
\hline Lack-of-fit & & 0.796 & 3 & 0.070 \\
\hline Pure error & & 0.200 & 4 & \\
\hline$R^{2}$ & 0.908 & & & \\
\hline $\operatorname{Adj}-R^{2}$ & 0.842 & & & \\
\hline AAD $(\%)$ & 7.36 & & & \\
\hline \multicolumn{5}{|c|}{ No2OS-1000 } \\
\hline Intersection & 7.334 & 312.009 & 1 & 0.000 \\
\hline $\mathrm{T}$ & -0.167 & 0.167 & 1 & 0.030 \\
\hline B & 0.117 & 0.082 & 1 & 0.098 \\
\hline TB & -0.025 & 0.003 & 1 & 0.748 \\
\hline $\mathrm{T}^{2}$ & -0.521 & 0.749 & 1 & 0.001 \\
\hline $\mathrm{B}^{2}$ & -0.071 & 0.014 & 1 & 0.459 \\
\hline Model & & 1.233 & 5 & 0.003 \\
\hline Residual & & 0.157 & 7 & \\
\hline Total & & 1.391 & 12 & \\
\hline Lack-of-fit & & 0.029 & 3 & 0.822 \\
\hline Pure error & & 0.128 & 4 & \\
\hline$R^{2}$ & 0.887 & & & \\
\hline $\operatorname{Adj}-R^{2}$ & 0.806 & & & \\
\hline AAD (\%) & 1.39 & & & \\
\hline
\end{tabular}


Fig. 1.
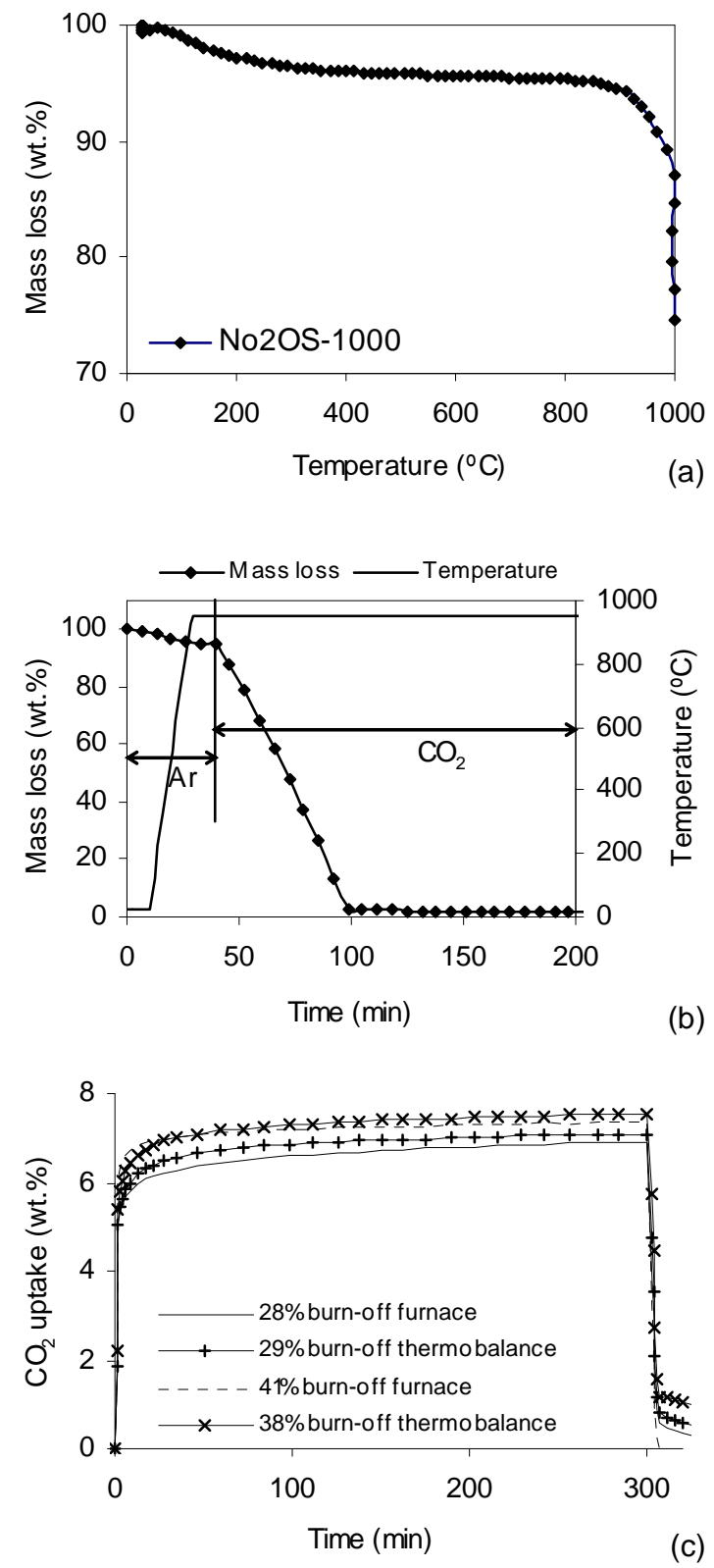
Fig. 2.
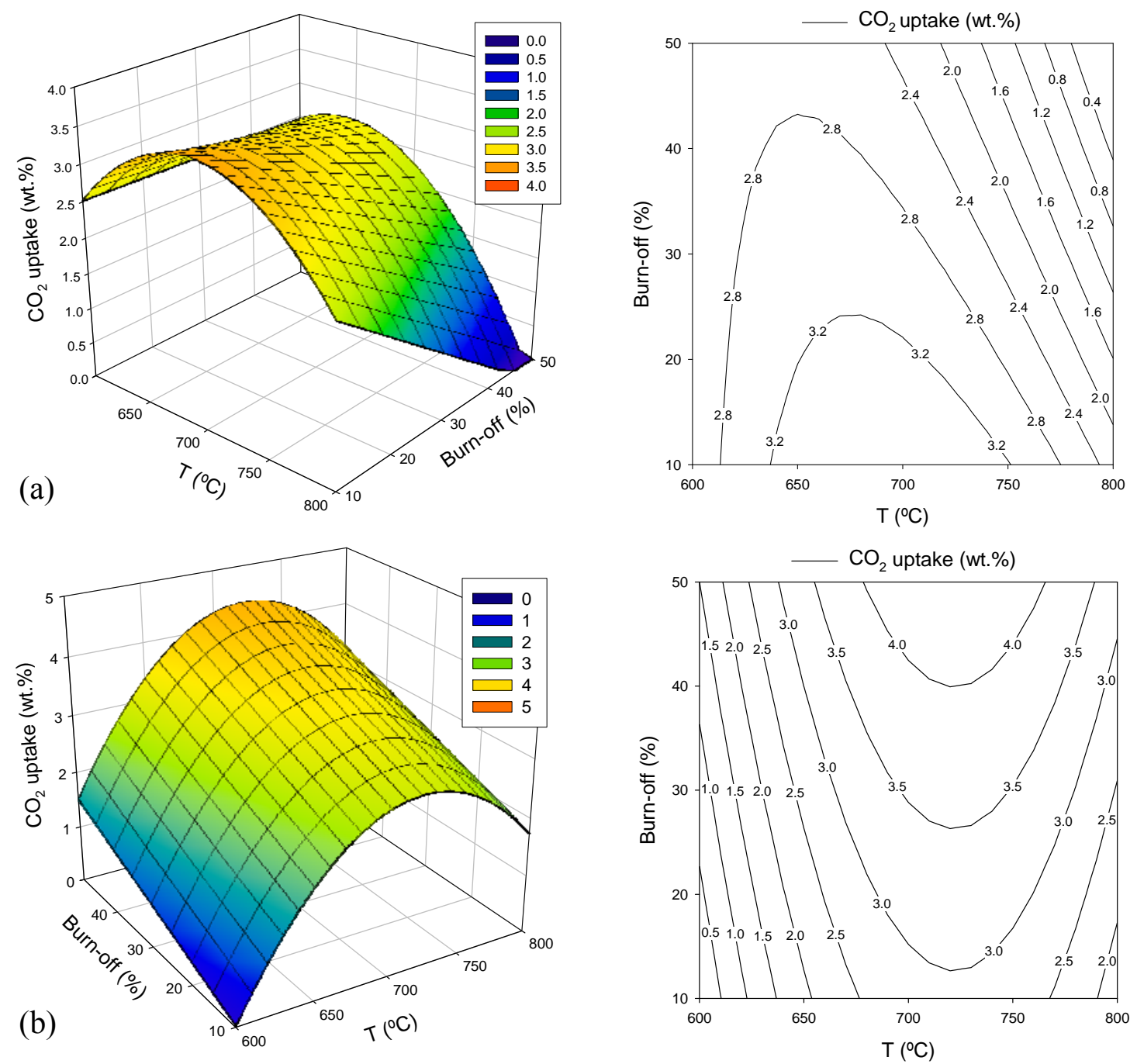
Fig. 3.
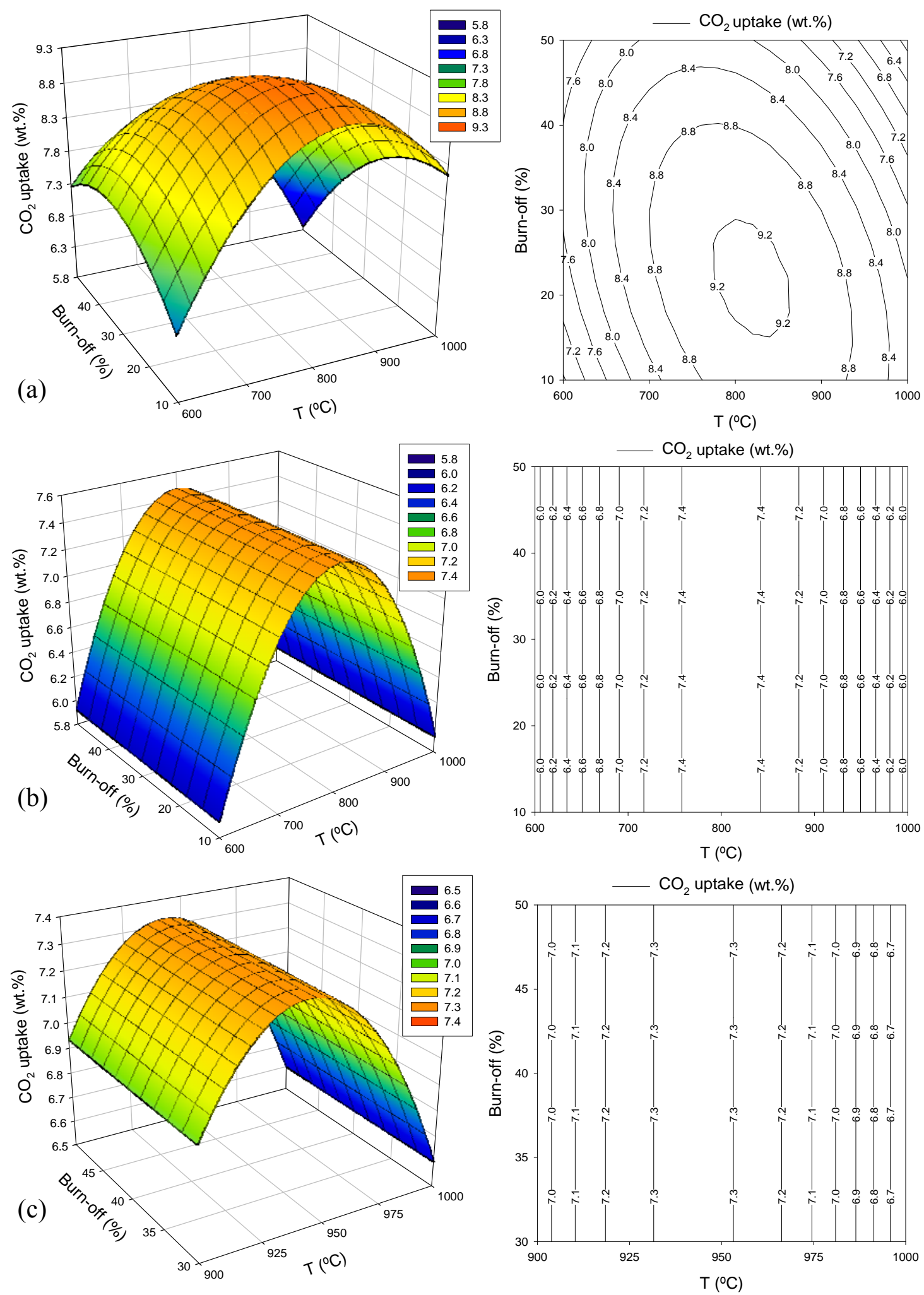